\title{
A CONSTITUIÇÃO DO PROFESSOR COMO TRABALHADOR
}

\author{
Áurea de Carvalho Costa \\ UNESP/BAURU-SP \\ aurea@fc.unesp.br \\ Adriana Maria Mattos Marafon \\ UNIMEP/PIRACICABA-SP \\ amarafon@unimep.br
}

\section{RESUMO:}

O presente texto surgiu como um exercício para responder uma indagação: Como se constituiu historicamente o professor enquanto trabalhador? Para contribuir à elucidação dessa indagação, procuramos situar esse profissional na divisão social do trabalho, em diferentes contextos históricos. Buscamos levantar elementos da sua constituição enquanto profissional desde o pólo do entendimento do mestre como um vocacionado, um profissional, com aptidões especiais numa visão inatista, até o pólo do profissional. Objetivamos contribuir para a análise sobre a configuração histórica do magistério como profissão e encerramos o texto apresentando a nossa tese de que o professor não pode ser considerado nem um vocacionado, nem profissional liberal prestador de serviços, mas o profissional da educação, com conhecimentos específicos e experiências que se constroem na trajetória de trabalho, e, na esfera social, como intelectual orgânico.

Palavras-chave: professor, magistério, licenciaturas

\section{THE CONSTITUTION OF TEACHER AS WORKER}

\begin{abstract}
:
This paper appeared like an exercise to answer a question: Wich's be constituted the teacher's like worker? How this place was been consisted historicaly? To contribute to briefing of this question, we look for to point out education's professional in differents historic contexts, looking the teacher since polo of professional whith a vocation and special aptitudes, till polo of professional whose activity includes comceptual, experience and social dimensions. We goal to contribute to analysis of neolibealism's effects about the teachers professional identity build, and we finish the paper presenting our tesis that teacher may not to be considered either like a vocacioned, neither a proletary, nor a lender of services, but an organic intelectual.
\end{abstract}

Keywords: teacher, teaching,

\section{1) Introdução}

Pode-se entender o magistério como o exercício de uma vocação? E, em decorrência disso, pode-se admitir a atividade de ensinar como a missão daqueles que teriam recebido um dom? Para responder a tais questionamentos, faz-se necessário refletir o magistério buscando problematizar a hipótese de que esta atividade foi se constituindo, inicialmente, como decorrente do dom, atributo do vocacionado, tendo como fundamento filosófico a verdade como revelação. Depois, como aptidão, em que o fundamento é a 
habilidade inata e, finalmente, como exercício de uma profissão, constituída socialmente, no interior de uma sociedade classista, entendimento construído a partir do referencial do materialismo histórico e dialético. Entretanto, há uma indagação anterior: quais são as origens de tal hipótese?

Franco (1993), ao analisar o "Segundo Tratado sobre o Governo", apontou as relações entre as categorias liberdade, igualdade, propriedade e natureza na doutrina liberal e como estas se combinam para lhe conferir uma organicidade peculiar. Uma das premissas da doutrina liberal, em sua versão clássica, é que o homem possui naturalmente a vocação para se constituir em proprietário desde o nascimento. Essa premissa sustenta-se no fenômeno da igualdade biológica, cuja argumentação fundamenta-se na origem natural comum de todos os homens. Tal premissa serviu a um fim: de instituir a noção de igualdade originária, biológica e genérica, como igualdade real. Entretanto, apesar de os homens serem iguais, enquanto membros de uma mesma espécie e partes do reino da natureza, cumprem de maneiras diversas o ciclo natural de apropriação e estabelecem uma relação com a natureza que os diferencia entre si, no que tange às diferenças de aptidões (FRANCO, 1993, p. 51).

Apesar de partir de uma premissa restrita à igualdade originária do homem, a lógica acima formulada tem uma finalidade: introduzir o conceito de igualdade diante do conceito de desigualdade, o de liberdade, diante do de coerção, e assim por diante. Não se trata de inversão de significado, mas de deslizamento de conceitos, como o que identificamos na configuração neoliberal que o liberalismo assumiu na atual conjuntura. Ocorre que só podemos conhecer esses conceitos mediante seus opostos.

O efeito produzido por tal ideologia é o que hoje chamamos por discurso peculiar ao capitalismo, em que as diferença individuais fundamentariam a existência de diferentes aptidões. Contudo, a identificação da aptidão a um valor sustenta-se na arbitrariedade, eis a inconsistência. A aptidão é assumida como uma construção, cuja base encontra-se além do domínio possível ao controle dos mortais - dom divino ou obra da natureza. É necessário considerar a aptidão como uma propriedade não inerente a todo indivíduo para transmutála numa forma de distinção daquele que a tem. A aptidão significa, sobretudo, uma forma de operar a identificação de indivíduos, tornando-se instrumento de distribuição destes na divisão social do trabalho.

Como se pode observar, os teóricos da doutrina liberal empregaram a prática do deslizamento dos conceitos de tal forma que a igualdade, tomada no liberalismo como igualdade de deveres sociais e oportunidades, postula que os diferentes talentos naturais levam os indivíduos a utilizarem, de formas diferentes, as oportunidades oferecidas pela sociedade, segundo suas diferentes aptidões. É nesses termos que a dimensão biológica da vocação - a aptidão - é incorporada e irradiada como uma verdade de status científico, construído no âmbito das ciências situadas no referencial teórico empirista.

MARAFON (2001, p. 21) faz uma análise histórica do conceito "vocação" na modernidade e nos informa que, da tradução do latim consiste numa ocupação contínua do homem sob a divisão do trabalho, fonte de seu sustento, destacando aqui, além da dimensão biológica, a dimensão social do conceito.

Dessa pesquisa, destacamos a palavra officium - com sentido de tarefas, obrigaçõese professio -referindo-se especialmente às obrigações dos seculares, que são os trabalhadores ligados ao clero - como os mestres, os escribas no Medievo e os devotados às outras tarefas, peculiares ao monastério - e, na modernidade, refere-se aos profissionais liberais.

Na conjuntura da reforma protestante, o termo "vocação" assumiu um novo sentido, uma vez que a qualificação e a especialização profissional passaram a ser requisitos para a 
eficiência da chamada racionalidade técnica no capitalismo ocidental, buscando as suas bases teóricas na doutrina liberal, de marca individualista, meritocrática e competitiva (MARAFON, op. cit.).

E qual é esse novo sentido? Vocação enquanto execução de um trabalho como fim em si mesmo, uma atitude. Trata-se de exercício de tarefas, o qual passa a envolver aptidões, competências, habilidades, como requisito para atingir eficiência e produtividade, tendo como referente a adaptação à sociedade capitalista. Isto significa, colocar a subjetividade do homem a serviço do capital?

Em suma, o que se produziu hoje sobre o conceito "vocação", objetivou-se na forma de hierarquias estabelecidas a partir do exame de competências e comportamentos características da subjetividade - condizentes com as profissões, de modo que a "vocação" constituiu-se, antes, como ideológia diversa do que como chamamento divino ou aptidão natural, uma vez que resulta da interação dos indivíduos entre si e com o meio natural e social em que se encontram inseridos (MARAFON, op. cit.).

Assim, constitui-se uma subjetividade que não é inata e, portanto, não pode aparecer como um conjunto de tendências naturais peculiares a cada um:

Só por meio da riqueza objetivamente desenvolvida do ser humano é que
em parte se cultiva e em parte se cria a riqueza da sensibilidade subjetiva
humana (o ouvido musical, o olho para a beleza das formas, em resumo
os sentidos capazes de satisfação humana e que se confirmam como
capacidades humanas). Certamente, não são apenas os cinco sentidos,
mas também os chamados sentidos espirituais, os sentidos práticos
(vontade, amor, etc), ou melhor, a sensibilidade humana e o caráter
humano dos sentidos, que vêm à existência mediante a existência do seu
objeto, por meio da característica humanizada. A formação dos cinco
sentidos é a obra de toda a história mundial anterior (MARX, 2001, p.
143-4, grifos do autor).

Enfim, toda sensibilidade desenvolvida por cada ser humano, no âmbito subjetivo, não se deve, necessariamente, aos fatores intrínsecos e à forma como o homem interage com a natureza, mas ao contexto em que cada sujeito se insere enquanto parte do gênero humano, uma construção social.

1) DO PRECEPTOR AO MESTRE: notas sobre a constituição profissional do professor na História

O problema da profissionalização da atividade de ensino articula-se profundamente com a natureza das relações entre os adultos que transmitiam os conhecimentos e as gerações mais jovens, pois é a partir desta realidade que o educador deverá se situar nas relações sociais e constituir a base da profissão, que é a relação triádica entre educador, conteúdos e educando. Tal tema demanda uma abordagem aprofundada que tem sido empreendida por didatas e historiadores da educação e sistematizadas em textos especializados. Contudo, cabe, neste estudo pontuar três caracterísitcas de tais relações até o medievo: assistemáticas, polarizadas entre educador e educando, não coletivas e não institucionalizadas (ALVES, 2005, P. 17-18).

$\mathrm{Na}$ antiguidade grega, a relação entre o pedagogo e o discípulo era permeada pela seguinte contradição: por um lado, a atividade do pedagogo permitia a opressão, devido ao uso da exigência menmônica e da coerção física como estratégias de ensino; por outro, os educandos eram os filhos dos senhores e os pedagogos, escravos de guerra. Portanto, eles mesmos oprimidos pelas próprias famílias onde educavam. Nesse contexto, a condição 
social do educador era peculiar, devido à própria concepção negativa de trabalho: além da figura do pedagogo, que se tornou escravo pelo fato de ser perdedor na guerra, havia a do mestre de escola livre, um homem de cultura, que elegia o ensino como seu ofício, em situações de dificuldades financeiras e descenso social de sua família. Havia preceptores que se enriqueciam devido a essa atividade laboral, entretanto, não escapavam ao preconceito social, pois, "Então, é coisa digna ensinar aos amigos e parentes, mas é vergonhoso ensinar por dinheiro e por pobreza. Também numa sociedade mercantil permanece por muito tempo o desprezo arcaico pelas atividades exercidas com fins de lucro." (MANACORDA, 1992, P. 63).

Sócrates debatia com os sofistas sobre a polêmica de se receber proventos para ensinar se constituiria numa prática não virtuosa, devido ao fato de que: 1) quando ensinamos, ao mesmo tempo, aprendemos, estabelecendo-se desde o início uma relação essencialmente de troca; 2) a posição do educando em relação ao educador é de subordinação e, nessa condição, o educador deve submeter seu educando de maneira virtuosa, ao invés de tirar proveito de sua ignorância. O filósofo afirma que a obtenção de proventos por meio do ensino se inseria na injusta lógica da justiça dos homens: a da conveniência do mais forte. Nesse sentido, aquele que ensina - o detentor do poder na relação professor e aluno - ao instituir como regra cobrar por essa atividade, o faz como exercício de dominação sobre aquele que não sabe:

[Trasímaco] -Que outra pena - respondi eu - senão aquela [o pagamento] que deve sofrer o ignorante? Devo aprender junto de quem sabe. É isso, portanto, o que eu julgo merecer.

[Sócrates]-És muito engraçado. Mas, além de aprender, terás de pagar também dinheiro (PLATÃO, s/d, p. 22).

O discípulo, ao pagar pelos ensinamentos do mestre, sofria duas penas: a primeira era a submissão ao mestre e a segunda, o pagamento em ií. $\mathrm{O}$ fato de o preceptor cobrar pelo ensino incorria num desvio na natureza da atividade de ensinar, pois tratava-se de atividade que deveria visar ao benefício do aprendiz, exclusivamente, e, de forma extensiva, à sociedade:

-Portanto, Trasímaco, nenhum chefe, em qualquer lugar de comando, na medida em que é chefe, examina ou prescreve o que é vantajoso para ele mesmo, mas o que o é para o seu subordinado, para o qual exerce a sua profissão, e é tendo esse homem em atenção, e o que lhe é vantajoso e conveniente, que diz o que diz e faz tudo o quanto faz (Idem, p. 31).

De fato, o que Sócrates objetava era a consideração do ensino como atividade mercenária, vez que, para o filósofo, tratava-se, antes, de oportunidade de exercício da subordinação do educando com a finalidade virtuosa de lhe proporcionar o aprendizado das artes liberais, de instauração de uma segunda natureza, a civilizada.

Na Idade Média, o magistério aparece como missão, materializada na tarefa do professor de auxiliar o aluno no processo de apreensão da verdade. O mestre já não é a fonte do conhecimento, mas um instrumento para se atingir a verdade, na medida em que o conhecimento verdadeiro pré-existe ao homem e é revelado por Deus aos iluminados:

É legítimo afirmar que um homem é verdadeiro professor, que ensina a verdade e que ilumina a mente, não porque infunda a luz da razão em outro, mas como que ajudando essa luz da razão para a perfeição do 
conhecimento, por meio daquilo que propõe exteriormente, tal como o diz São Paulo (Ef. 3,8) "A mim, que sou ínfimo entre os santos, foi dada esta graça: a de iluminar a todos etc" (TOMÁS DE AQUINO, 2001, p. 35 , grifos nossos).

Observe-se que, para Tomás de Aquino, o professor ensina a verdade que ilumina a mente, não podendo infundir a razão no aluno que não a tem dentro de si. Parece permanecer a idéia socrática de que o aprendizado depende do metal que o indivíduo traz na constituição de sua alma, ou seja, depende do seu talento, uma pré-disposição para a apreensão da verdade que não é dada a qualquer ser humano.

No século XIII, o magistério era praticado predominantemente por clérigos e, mesmo os leigos que se dedicavam a essa atividade, tendiam a viver sob preceitos morais estabelecidos socialmente para os primeiros, o que pode ter relação com o fato de o ensino ser considerado como vocação, ou seja, chamado divino ${ }^{1}$. O ensino universitário foi constituído no seio da igreja católica: a universidade de Bolonha nasceu como um centro católico de estudos jurídicos e depois, em 1352, fundou-se uma faculdade de teologia, devido à influência do papa Inocêncio VI. Antes mesmo, no século XII, o papa Inocêncio III criara a universidade de Paris e, "a Universidade de Paris ter-se-ia constituído sem a intervenção dos papas, mas é impossível compreender o que lhe assegurou um lugar único entre todas as universidades medievais se não se levar em conta a intervenção ativa e os desígnios religiosos nitidamente definidos do papado" (VERGER, 1990, p. 485).

A hegemonia da igreja católica sobre os estudos superiores era o tempo todo ameaçada, mediante as lutas pela laicização do ensino universitário, pelo interesse do poder Estatal em financiá-los e o interesse de alunos e professores em fundar instituições independentes (Idem, p. 26030). Naquele momento, em que os estudos universitários ainda não tinham o sentido de Universidade, qual se apresenta a partir da modernidade, a Universitas, ou Studium Generale, ou Comune referia-se a um "conjunto de pessoas, mestres e alunos, que participam do ensino dado nessa mesma cidade" (GILSON, 2001, p.483).

Durante toda a Idade Média, a presença de clérigos na história da educação é muito marcante e pode ser representada por pensadores como Santo Agostinho, São Tomás de Aquino, São Boaventura, Santo Ambrósio, Santo Anselmo de Cantunária, Guilherme de Okcam e outros (Idem, p. 492 e ss.).

Quanto à remuneração, o professor podia receber contribuições de seus alunos após as aulas, mas não tinha um provento de valor fixo e frequência periódica, que caracterizasse uma relação de trabalho salariado ${ }^{2}$. Nesse momento, retoma-se o debate sobre se era moral ou amoral por parte dos mestres receber para ensinar ou se a Igreja é quem deveria remunerar quem ensina. Entendemos que isso suscitava uma discussão mais profunda sobre se o magistério deveria ou não se constituir em profissão, tendo em vista seu caráter de dom divino, recebido gratuitamente, para assim ser oferecido (VERGER, op. cit.).

Naturalmente, não se deve olvidar, que no contexto histórico medieval, o trabalho segue tendo um caráter negativo, de modo que era considerado como atividade própria dos estratos inferiores da sociedade. $\mathrm{O}$ fato de que os candidatos a professores eram filhos de nobres e burgueses abastados permite-nos a inferência de que, nesse momento, estes ocupavam um lugar privilegiado na divisão social do trabalho.

Indagamo-nos se, na modernidade, a sociedade ocidental teria herdado o préconceito de que o requisito para se tornar um bom professor seria o dom e/ou a aptidão para ensinar, e apresentamos a seguinte hipotese: devido ao fato de que o dom é entendido como dádiva divina ${ }^{3}$, na perspectiva metafísica, e a aptidão é vista enquanto atributo da 
natureza, na perspectiva inatista, tem-se a justificativa ideológica para que aqueles atributos subjetivos sejam assumidos como condicionantes da formação objetiva do professor no liberalismo.

Ante o exposto, entendemos que se trata de uma ideologia, cujo fundamento é o que estabelece como natural a igualdade biológica e a desigualdade social entre os homens na doutrina liberal. Considerar o professor como um vocacionado é situá-lo na divisão social do trabalho capitalista fixando-o num determinado papel social tão diferenciado - de missionário - em relação aos trabalhadores em geral. Isso suscita outra indagação: nessa condição de signatário de uma missão, o professor seria atingido de forma diversa pelas injunções que se abatem sobre a totalidade da classe trabalhadora, no que se refere à remuneração, às condições e à precarização do trabalho?

\section{2) O professor na divisão social do trabalho capitalista}

A gênese da divisão social do trabalho se confunde com o surgimento da propriedade privada: o objeto da produção não tem a função social de contribuir para a satisfação das necessidades do gênero humano, como uma totalidade, mas a produção para a satisfação de necessidades particulares e imediatas de cada indivíduo. No modo de produção capitalista, a sociedade é reduzida à sociedade civil, em que os indivíduos particulares realizam trocas entre si para satisfação de necessidades egoístas, sob a mediação do dinheiro: "A sociedade - como surge aos olhos do economista - é a sociedade civil, em que cada indivíduo constitui uma totalidade de necessidades e só existe para ele à medida que se tornam meios uns para os outros" (MARX, 2001, p. 160).

N'O Capital, Marx define a divisão social do trabalho, no capitalismo, a partir da diferenciação em relação à divisão do trabalho na manufatura, devido a diferentes condicionantes. Historicamente, a divisão manufatureira do trabalho situa-se no seio das corporações de ofício, enquanto que a divisão social do trabalho de marca capitalista, na oposição entre trabalho no campo e na cidade, desde o momento da constituição do trabalhador urbano, como decorrência da expulsão do campesinato, que já se observa em meados do século XV, no ocidente (MARX, 1998,p. 264).

Do ponto de vista processual, enquando na divisão manufatureira há um encadeamento em que o produto de uma etapa de um processo de produção constituise em matéria prima para outro, de modo que todo o processo produtivo objetiva-se num produto final, na social, acontece a articulação dos diversos ramos da produção, de modo que ocorre um encontro de indivíduos, portadores de necessidades particulares, vendedores de produtos excedentes, as mercadorias, enquanto que, na manufatureira. Enfim, a divisão social do trabalho torna-se mais complexa em diferentes ramos da produção, como o comércio, a indústria e a agricultura, para penetrar à organização da produção e proporcionar o aparecimento dos ofícios e das profissões, limitando os indivíduos às esferas profissionais particulares (MARX, 1998, p. 406 e ss.).

A divisão manufatureira do trabalho segmentou o corpo de conhecimentos necessários para a conformação do ofício. Por meio da parcelização, as tarefas, antes elaboradas pelo artesão, passaram a ser desenvolvidas por vários trabalhadores parcelares na fábrica, não especializados, dando origem a uma multiplicidade de ofícios. Isso ocorreu quando o capitalista tornou-se proprietário da oficina, da matériaprima e dos instrumentos de trabalho. A partir daí, contratou artesãos para fabricar os produtos e impôs uma organização do trabalho de tal modo que a classe trablahadora, constituída com um corpo de conhecimentos sobre o trabalho que a possibilitava o controle sobre o processo de trabalho do começo ao fim, após algumas gerações de 
implementação a parcelizaçãor foi impingida a se dedicar a tarefas parciais na produção de uma determinada mercadoria. Nesse momento, a alienação no trabalho se efetiva como esvaziamento de seus conteúdos e um não reconhecimento, pelos trabalhadores, do produto que eles mesmos produzem em conjunto. Tal processo de alienação tem tornado a classe trabalhadora cada vez mais dependente das trocas que se dão na sociedade, segundo as lei de mercado, impostas como alternativa única de sobrevivência (Idem, p. 408).

A decorrência desse processo de alienação consiste numa diversificação dos talentos humanos como um efeito da divisão social do trabalho e não a sua causa. Os intelectuais orgânicos do liberalismo trabalham na constituição da ideologia de que o talento seria algo inato, que teria como consêquencia a divisão social do trabalho, quando, na verdade, é o contrário que ocorre. Os atributos humanos são constituídos no seio das relações sociais, e geram intercâmbios, uma vez que " os talentos humanos e as formas de atividade mais diversos são de mútua utilidade, porque lhes é possível juntar os diferentes produtos numa massa comum, onde cada qual pode comprar. Assim como a divisão do trabalho nasce da disposição para a troca, assim também ela cresce e é delimitada pela extensão da troca, do mercado (MARX, 2001,p. 164, grifos do autor).

Dessa discussão, destacamos o surgimento da idéia de trabalhador especializado, que vai originar o ofício e a profissão. Durante todo o século $\mathrm{XX}$, desenvolveu-se um debate sobre a qualificação, diretamente influenciada pelas variações na organização do trabalho fabril. No taylorismo, desenvolveu-se uma tecnologia para elevar os níveis de produtividade do trabalhador, parcelando-se, cada vez mais, suas tarefas e controlando seus tempos de atividade e repouso, com vistas a elevar os níveis de exploração da sua força física. No fordismo, a idéia de qualificação refere-se à formação de trabalhadores especializados em determinadas tarefas na fábrica, aprofundando, ainda mais, a parcelização do trabalho e exigindo, nessa conjuntura, além da força física, a formação técnica como recursos para a ampliação da expropriação de mais-valia. Saliente-se que, no contexto do pós $2^{\mathrm{a}}$ Grande Guerra, o conceito qualificação foi utilizado como recurso ideológico do capital para fragmentar a classe trabalhadora. A partir de tal conceito, o capitalismo instituiu uma polarização: o pólo do perfil de trabalhador requerido e o pólo da formação técnica, da experiência acumulada e o próprio lugar na divisão social do trabalho que cada trabalhador ocupa, aprofundando a hierarquização no seio da classe trabalhadora ( Cf. RAMOS, 2001; PEÑA CASTRO, 1996).

A partir do conceito qualificação, dá-se a categorização com vistas a apreender diferentes níveis de qualificação profissional determinadas de acordo com a formação:

Profissões, ofícios e empregos se diversificam também segundo o tipo de formação requerida, a duração da aprendizagem e o nível de qualificação que resulta. Contrariamente a uma opinião difundida, a formação em escola técnica ou em uma empresa, é o elemento decisivo das capacitações profissionais e do grau de qualificação alcançado. $\mathrm{O}$ profissional, em qualquer ramo de atividade e qualquer emprego, é o trabalhador (provisto) de uma experiência (educada). A extensão do ensino técnico e dos (médios) de aperfeiçoamento desde há vinte anos, em todos os países industriais, basta para prová-lo. $\mathrm{O}$ aumento do número de diplomas e certificados profissionais emitidos na França, para uma população ativa que cresce ao máximo, se produz no mesmo sentido. É verdade que o aprendiz muda de modalidades em grande medida. Proporcionalmente se termina com menos frequiência depois de dois ou três anos de ensino profissional e com maior frequiência se acelera, prolonga e mantêm sessões de aperfeiçoamento, quase sempre na empresa (NAVILLE; FRIEDMANN, 1992, p. 232, grifos nossos) 
A qualificação técnica é, por sua vez, determinante da situação do trabalhador num posto de trabalho correspondente à sua formação e, no limite, determinante de sua profissão:

De qualquer maneira, segue sem uma forma essencial de aquisição de capacidades que fazem de seu possuidor um profissional e um homem de ofício. A diminuição do tempo de adaptação imediata a certas tarefas não é incompatível com esta tendência, mesmo nas tarefas de vigilância que necessitam, pelo contrário, quase sempre, de longos períodos de familiarização e de experiência. Pela regra geral, poderíamos dizer que a atividade de trabalho se parece tanto mais com uma profissão ou a um verdadeiro ofício quanto mais prolongado é o tempo e mais amplos os conhecimentos que caracterizam a aquisição de seu domínio (Idem).

A partir dos anos 1970, nos países de capitalismo central, e 1980, no Brasil, assistimos a uma nova crise do capital, decorrente da crise energética em todo mundo e da queda na taxa de lucros, um fenômeno tendencial no capitalismo. Tal conjuntura demandou novas formas de organização do processo produtivo, e nele, a nova organização do trabalho, em que se deu a relativização dessa categorização das profissões entre os trabalhadores especializados. Os trabalhadores diretamente ligados à produção foram submetidos a um processo de restruturação da organização do trabalho fabril que rompe com a idéia de trabalhador qualificado especializado, em prol de uma formação dos trabalhadores de natureza polivalente, que os prepare para situações novas, administração de conflitos, detecção e resolução de problemas, elaboração de propostas criativas, tendo em vista o aumento da produtividade.

Mediante a imposição à escola capitalista de responder a essa demanda, tal instituição assume a tarefa de formar trabalhadores com competências aplicáveis às diferentes situações de trabalho, tornando-os flexíveis, para responder à demanda do capital a partir da instituição da organização em células nas quais os operários passam a exercer múltiplas funções. Manifesta-se, mais uma vez, a subsunção da escola ao mundo do trabalho, porém, com caracterísitas específicas da conjuntura neoliberal. Nesse quadro, é possível que a nova organização do trabalho possa atingir a formação e a atuação do professor? Uma vez explicitada nossa concepção de divisão social do trabalho, indagamos qual é o lugar do professor nessa divisão, no neoliberalismo?

A partir do anos 1970, houve a superação do modelo de Estado do Bem-Estar, em favor de outro menos interventor nas questões concernentes ao mercado - o Estado Mínimo. Nesse modelo, a escola tem sido considerada como prestadora de serviços, devido à própria mudança na função Estatal, de garantidor de direitos para provedor uma estrutura para o mercado, em que suas instituições passam a ser organizadas como prestadoras de serviços, exclusivos do Estado ou não. "Isso, aliás, mostra que Hayek, a despeito de todo o seu determinado abandono da 'miragem de justiça social', não se limitou a retroceder a um puro favorecimento de laissez-faire ou ao Estado Vigia noturno (MERQUIOR, 1991, p. 191).

O Estado, segundo esse modelo, passou a restringir sua atuação no âmbito social e a assumir as tarefas de fomentador e avaliador de políticas públicas no âmbito social. Consequentemente, a educação torna-se serviço, apelando às parcerias com a iniciativa privada para a implementação de políticas de serviços educacionais.

A classe trabalhadora, desde meados do século XIX, empreende lutas pelo direito à educação, buscando arrancá-la ao Estado Burguês nas condições de pública, gratuita, universal e laica (ALVES, op. cit.). Contudo, desde a segunda metade do século XX, o 
professor tem atuado profissionalmente numa escola onde a formação básica, de direito a ser garantido pelo Estado, tem sido convertida pelo Estado neoliberal em serviço não exclusivo daquele. Essa transmutação do direito à educação escolar em serviço educacional constitui-se em um aspecto importante da mercantilização no âmbito da educação e coloca novas exigências aos educadores.

Se nos detivermos mais pormenorizadamente na dinâmica interna da instituição escolar, constataremos que, mesmo antes da reforma nas funções do Estado, que marcou a passagem do século XX para o século XXI, a organização taylorista-fordista do trabalho já guardava uma racionalidade que cedo se introduziu na organização do trabalho escolar, com vistas a aumentar a produtividade, ampliando as tarefas do professor na escola e fora dela, otimizando o seu trabalho de atendimento a números cada vez maiores de alunos, e buscando níveis de controle cada vez maiores sobre seu trabalho. Nesse sentido, o tecnicismo na educação, sob inspiração taylorista-fordista, prestou uma importante contribuição para a racionalização do trabalho na escola.

As novas demandas ao profissional da educação no neoliberalismo, de mercantilização do ensino, notadamente o escolar, forjou a necessidade de uma transformação nos processos de formação dos professores. Mais uma vez, uma metodologia de organização do trabalho no mundo da produção é introduzida na organização do trabalho escolar e passa a se constituir em eixo para a elaboração de diretrizes em todos os níveis e modalidades de ensino, inclusive a formação e a atuação profissional de professores (COSTA, 2004).

No que tange aos profissionais da educação, por vezes, assistimos a um processo de degradação das condições de trabalho que se concretiza sob duas formas. A primeira forma consiste no esvaziamento de conteúdos do seu trabalho, transformando-o em mero técnico, o que concorre para a destituição de sua autonomia na escolha e seleção dos conteúdos. Os instrumentos de concretização disso são: a formação dos professores em licenciaturas cada vez mais aligeiradas, que os leva a uma maior dependência dos livros didáticos; o estabelecimento dos parâmetros curriculares nacionais, que elegem determinados eixos transversais como os privilegiados na seleção de organização dos conteúdos; a prática das avaliações institucionais, como o exame nacional do ensino médio, o sistema de avaliação do ensino básico, o sistema de avaliação do rendimento escolar de São Paulo e outras, que classificam as escolas a partir dos desempenhos dos alunos e, aferem esses desempenhos a partir de competências pré-determinadas pelos avaliadores. A outra forma é o rebaixamento do salário e condições laborais, ao oferecer salas superlotadas tornando a escola mais produtiva do ponto de vista de fluxo, como se fosse suficiente aferir o número de concluintes para se ter uma dimensão exata da qualidade da escola (NOVAES, 1987, p. 50$52)$.

E, mesmo no contexto da reestruturação produtiva, que sucedeu a crise do capitalismo da década de 1970, o professor não escapou à influência da organização flexível do trabalho sobre a sua prática docente. No texto do parecer CNE/CP 009/2001, o qual estabelece as diretrizes para formação de professores, esse profissional, além da regência, também é convocado a atuar junto à comunidade, a fazer pesquisa, a envolver-se em processos de educação continuada e na atualização profissional, bem como ter uma formação flexível para que possa atuar em diferentes instituições, com alunos que apresentam diferentes necessidades, a utilizar as tecnologias da informação e gerir as situações escolares, tudo isso num contexto em que permanece a precariedade de salários e condições de trabalho (COSTA, 2004, p. 8).

Entretanto, há uma contradição: se, por um lado, o capital esforça-se por apreender do trabalhador seus saberes sobre o trabalho, por outro, jamais consegue o domínio completo 
sobre eles (ROSA, 1998 p. 130 e ss). No que tange, especificamente, ao trabalhador da educação, essas tentativas de destituir o professor de sua função de intelectual orgânico não logram êxito: ele continua tendo ascendência sobre os alunos e a estratégia mais recente do Estado neoliberal de interferir nisso é estabelecendo políticas que visam ao oferecimento de uma formação inicial empobrecida, alienada dessa função social, reduzindo-o a técnico de alto nível:

A política do MEC reforça o aligeiramento da formação de professores quando, por exemplo, valoriza os modelos institucionais alternativos de formação de professores para a educação básica; possibilita a criação dos institutos superiores de educação; regulamenta a formação de professores para a educação básica num corpo de complementação; estabelece consórcios com instituições de ensino para certificar docentes por meio de universidade virtual (MINTO; MURANAKA, 1991, p. 142).

LE BOTERF (2003, p. 22-3) resgata o termo profissão desde a Idade Média, como algo que diz respeito aos saberes sobre o trabalho específicos de um grupo uma ordem e isso é resguardado pela lei, segundo a qual os profissionais só poderiam exercer a profissão mediante licença. Outrossim, ele define ofício como conjunto de saberes que se obtém a partir da experiência - o saber-fazer. De início, o autor estabelece uma hierarquização entre o profissional (com os saberes intelectuais) e o oficial (com saberes práticos).

Conforme o autor, "Profissionalismo" é uma idéia que se desenvolveu na França, num contexto de crise do desemprego e de busca pela conciliação entre os interesses da classe trabalhadora - de serem reconhecidos a partir de sua qualificação - e os interesses do capital - de obter trabalhadores cada vez mais polivalentes. Ele propõe o "profissionalismo" e a "situação profissional" como conceitos representativos de uma evolução em relação à idéia de profissional. Entendemos, assim, que o autor reedita o conceito de ofício sob a forma de "profissionalismo". Para ele, o profissional da atualidade deve ter uma gama de competências que o permita competir por empregos em diferentes lugares, vender-se, ter empregabilidade, em vez de uma qualificação. É a valorização dos saberes práticos, em detrimento dos conhecimentos sobre o trabalho (Idem, p. 24).

Com relação ao profissional da educação, como em outras situações profissionais, o apelo é para que o trabalhador esteja em estado de permanente requalificação. E, conforme analisaram MINTO \& MURANAKA (1991), tal entendimento está presente nas políticas públicas brasileiras de formação de professores de educação básica, em caráter de complementação. O que se tem em vista, especificamente, são as necessidades do mercado de trabalho capitalista, cambiante e subordinador da educação ao mundo do trabalho.

Enfim, denomina-se "profissionalismo" a capacidade de um indivíduo vender sua força de trabalho nesse mercado excludente, aproximando-se do modelo de profissional liberal, no sentido de prestador de serviços, com plasticidade para se adaptar às variações do mercado:

A identidade profissional é construída em relação a um projeto, a um produto, a um resultado esperado ou a um serviço para um cliente. O profissional é solicitado a contribuir para processos interofícios, a não mais se limitar a um posto de trabalho, mas intervir em processos e ser eficiente em interoperações. As etapas de sua carreira não são fixadas de antemão: resultam dos percursos a definir progressivamente, dentro ou fora da empresa. Um excelente profissional, mesmo que tenha "sido instruído" em uma determinada empresa, saberá "vender-se" no mercado de trabalho graças ao conjunto de competências que possui. $\mathrm{O}$ profissionalismo não deve excluir a referência a um ofício de origem. $\mathrm{O}$ 
ofício é fonte de identidade. É uma comunidade de origem e de competências. $\underline{\mathrm{O}}$ profissional se caracteriza por uma forte "empregabilidade". Possui a dupla característica de dominar bem suas competências e de ter suficiente recuo em relação a elas para poder adaptar-se a mudanças de empregos ou de setores de atividade. Ele sabe "manter-se preparado" para estar pronto para mudar. À imagem dos esportistas, "mantém-se em forma para". Seu potencial torna-o disponível para evoluir, para ser "reempregável" em outra empresa (LE BOTERF, 2003, p. 23, grifos nossos)

Isso justifica a relativização da importância dos conteúdos e a supervalorização da dimensão prática do trabalho pedagógico, presente na legislação que regulamenta as licenciaturas no Brasil, a partir de 2002 (BRASIL, 2002).

O professor, na contemporaneidade, apresenta-se sob novas formas: como um trabalhador autônomo, sem direitos e garantias legais, que se submete às incertezas das leis do mercado, por exemplo, os pedagogos, que abrem consultórios para atendimento de dificuldades de aprendizagem; os Educadores Físicos, que se empregam como personal trainer; os licenciados que sobrevivem oferecendo serviços na forma de aulas particulares; os professores que se submetem a contratos como prestadores de serviços com inscrição municipal ou contratos por tempo determinado e outras formas de exercício profissional da docência, marcadas pela instabilidade e precarização de direitos do trabalho.

Quando se estabelece estritamente esse perfil profissional como o desejável, rompese com o conceito de qualificação, o qual, na verdade, guarda 3 dimensões: a conceitual, que se refere aos conhecimentos teóricos e técnicos sobre o trabalho; a da experiência, relativa aos saberes práticos; e a social, ou seja, a consciência de seu papel social a partir do fato de ser um profissional, que se refere à importância social da profissão. O mercado de trabalho tende a tornar-se cada vez mais plástico e elástico, demandando trabalhadores, ora com umas competências, ora com outras e, por isso, forte capacidade adaptativa. Nessa conjuntura, a educação permanente, a formação continuada, a capacitação a reciclagem de profissionais são imposições do mercado de trabalho aos trabalhadores, para que o recurtamento e a seleção de profissionais se dêem segundo critérios sempre variantes, conforme as demandas de cada momento, subsumindo-se e esvaziando-se a formação inicial, cada vez mais aligeirada.

\section{Considerações finais}

Para exercer sua função social, não basta ao professor uma formação estritamente técnica, pragmática, voltada para a atuação como mero vendedor de serviços no mercado. Indagamos se ofício e profissão não seriam duas dimensões de um mesmo objeto, e se a idéia de profissional não ultrapassaria a polarização entre o detentor de saber e o prestador de serviços. Se o ofício é algo ligado à virtude do cumprimento do dever, que apela à ética, e profissão relaciona-se à dimensão de atividade para prover o sustento, utilizando um corpo de conhecimentos específicos para o profissional cumprir sua função social, a partir de um lugar na divisão social do trabalho, o professor contém essas duas dimensões. Ele se distingue de todos os outros profissionais que trabalham tendo como objeto a transmissão da informação, pelo fato de que o seu trabalho vivo ultrapassa a dimensão da instrução, buscando seus nexos com um processo educativo mais amplo, na escola:

A cosnciência individual da esmagadora maioria das crianças reflete relações civis e culturais antagônicas às que são refletidas pelos programas escolares: o "certo" de uma cultura evoluída torna-se "verdadeiro" nos quadros de uma cultura fossilizada e anacrônica, não existe unidade entre escola e vida, por isso, não existe unidade entre instrução e educação. Daí porque é possível dizer que, na escola, o nexo instrução-educação somente pode ser 
representado pelo trabalho vivo do professor, na medida que o mestre é consciente dos contrastes entre o tipo de sociedade e de cultura que ele representa e o tipo de sociedade e de cultura representado pelos alunos, sendo também consciente de sua tarefa, que consiste em acelerar e em disciplinar a formação da criança conforme o tipo superior em luta com o tipo inferior (GRAMSCI, 1991, p. 131).

Concluímos que o professor é um trabalhador sujeito às vissicitudes impostas pelo capital, cuja profissão não escapa aos antagonismos de classe, o que aparece de forma muito incisiva no âmbito das instituições privadas de ensino, mas não deixa de se manifestar também nas públicas, onde um Estado capitalista utiliza-se, cada vez mais das estratégias do mundo da produção para explorar e oprimir seus funcionários. A título de ilustração, podemos citar toda a legislação que normatiza a atividade profissional do professor na escola pública, no sentido de ampliar as possibilidades de exploração e retirar direitos do trabalho, como a retirada de direitos dos profesores do sistema público estadual de ensino paulista ( CF. SÃO PAULO, 2008a, 2008b).

Entretanto, os professores se enquadram no grupo dos profissionais que se caracterizam pelo exercício do trabalho intelectual como ofício:

Todos os homens são intelectuais, poder-se-ia dizer então; mas nem todos desempenham na sociedade a função de intelectuais. Quando se distingue entre intelectuais e não-intelectuais, faz-se referência, na realidade, tão-somente à imediata função social da categoria profissional dos intelectuais, isto é, leva-se em conta a direção sobre a qual incide o peso maior da atividade profissional específica, se na elaboração intelectual, ou se no esforço muscular-nervoso. Isto significa que é possísivel falar em intelectuais, mas é impossível falar em não-intelectuais. Mas a própria relação entre o esforço de elaboração intelectual-cerebral e o esforço de muscular-nervoso não é sempre igual; por isso, existem graus diversos de atividade específica intelectual (Idem, p. 7).

Nessa condição, um intelectual tradicional, como o professor assume a característica de intelectual orgânico, cuja peculiaridade é ser um produtor de consensos referentes ao estabelecimentos de ideologias de uma ou outra classe social, para além de um profissional qualificado, portanto, com uma dimensão política (Id. p. 6)

Enfim, os professores são intelectuais que atuam necessariamente a partir de uma filosofia de educação que traz consigo uma concepção de homem e de sociedade. O professor possui a prerrogativa da formação (ou deformação) das futuras gerações na escola.

Embora o professor, como qualquer outro profissional, não deixe de ser um vendedor de força de trabalho, pois isso é constituinte da classe trabalhadora, no modo de produção capitalista, ao exercer a profissão, tem a tarefa de não permitir que os critérios imediatistas e utilitaristas do mercado condicionem a sua atuação profissional, destituamno de peculiaridades que lhe conferem uma natureza específica. Mediante o exposto, concluímos que a luta dessa categoria pela afirmação de seu estatuto profissional concretiza-se na preservação do ensino presencial, garantindo a relação professor-aluno num contexto de sala de aula; pela não distorção do professor em gerente de uma classe, pela superação da perspectiva que reduz o conhecimento a informações e habilidades, pela formação inicial e continuada que o prepare para ser um intelectual de cultura geral e cumprir seu papel histórico.

É preciso que a categoria recuse a mistificação de que o magistério é um dom, uma vocação, numa perspectiva quase que de sacerdócio, não aceite a formação inicial para o magistério com esvaziamento dos conteúdos de sua formação, pois são essas as justificativas ideológica para que a sociedade capitalista exija do professor o execício da 
profissão sob condições de trabalho cada vez mais rebaixadas, com aviltamento dos salários.

Agradecemos aos professores Dr. Fernando Bastos e Dr ${ }^{\mathrm{a}}$ Rosa Manzoni, do Depto de Educação da UNESP/BAURU, pelo trabalho de revisão.

\section{Referências Bibliográficas}

ALVES, G.L. A produção da escola pública contemporânea Campo Grande: Editora da UFMS; Campinas: Autores Associados, 2001.

ARISTÓTELES Política. São Paulo: Martin Claret, 2001. (Obra prima de cada autor, $61)$.

BARROSO, J. Gestão local da educação: entre o Estado e o mercado, a responsabilização colectiva. In: MACHADO, L. M.; FERREIRA, N. S. (Orgs.) Política de educação, política de gestão: dois olhares. Rio de Janeiro: DP\&A, 2002.

BRASIL, Ministério da Educação - Conselho Nacional de Educação. Parecer CNE/CP 009/2001 que estabelece as diretrizes curriculares para a formação de professores de educação básica em nível superior, curso de licenciatura, graduação plena. Brasília, 2001.

BRASIL, Ministério da Educação - Conselho Nacional de Educação. Parecer CNE/CP 01/2002 que estabelece as diretrizes curriculares para a formação de professores de educação básica em nível superior, curso de licenciatura, graduação plena. Brasília, 2002.

GILSON, E. A filosofia na idade média. São Paulo: Martins Fontes, 2001. (Paidéia).

GRAMSCI, A. Os intelectuais e a organização da cultura. 8.ed. Rio de Janeiro: Civilização brasileira, 1991.

JAEGER, W. Paidéia: a formação do homem grego. São Paulo: Martins Fontes, 1986.

LE BOTERF, G. Desenvolvendo a competência dos profissionais. 3.ed. (rev. Amp.) Porto Alegre: Artmed, 2003.

MANACORDA, M. A . História da Educação: da antiguidade aos nossos dias. 3.ed. Campinas: Cortez/autores associados, 1992). (Educação Contemporânea; Memória na Educação).

MARAFON, A. C. M. O discurso acerca da vocação. In: Vocação matemática como reconhecimento acadêmico. Tese (Doutorado em Educação Matemática, Faculdade de Educação) Universidade de Campinas, SP, 2001.

MINTO, C. A. MURANAKA, M. A. S. Políticas públicas atuais para a formação de profissionais em educação no Brasil. Universidade e Realidade. I (1), fev. 1991. Brasília. P. 134-144.

MARX, K. Manuscritos econômico-filosóficos. São Paulo: Martin Claret, 2001. (Obraprima de cada autor).

MARX, K. O Capital. Livro primeiro, volume II. 16.ed. São Paulo: Civilização Brasileira, 1998.

MERQUIOR, J. G. O liberalismo: antigo e moderno. Rio de Janeiro: Nova Fronteira, 1991. 
NAVILLE, P. \& FRIEDMANN, G. Tratado de sociologia del trabajo. México: Fondo de Cultura Económica, 1992:232.

PLATÃO A república. 6.ed. Lisboa: Fundação Caloute Gulbenkian.

PEÑA CASTRO, R. Tecnologia, trabalho e educação (indeterminações) Cadernos da ANPED, nº 6 , out., 1994, p. 29-53.

Desvalorização social do trabalho e ilusória centralidade da educação. Universidade Federal de São Carlos - Centro de Educação e Ciências Humanas, São Carlos, 1996, mimeografado.

RAMOS, M. N. A pedagogia das competências: autonomia ou adaptação? São Paulo: Cortez, 2001.

ROSA, M. I. Do governo dos homens: as "novas responsabilidades" do trabalhador e o acesso aos conhecimentos. Educação e sociedade, 64, 1330-147.

SÃO PAULO LEI COMPLEMENTAR № 1041 DE 14 DE ABRIL DE 2008a. Dispõe sobre o vencimento, a remuneração ou o salário do servidor que deixar de comparecer ao expediente em virtude de consulta ou sessão de tratamento de saúde e dá providências correlatas.

SÃO PAULO DECRETO No 53.037, DE 28 DE MAIO DE 2008b. Dispõe sobre a regionalização dos concursos públicos para provimento de cargos do Quadro do Magistério, da Secretaria da Educação, define normas relativas a remoção, a substituição e a contratação temporária de docentes e dá providências correlatas.

TOMAS DE AQUINO Sobre o ensino (De magistro) - Os sete pecados capitais. São Paulo: Martins Fontes, 2001. (Clássicos da filosofia)

VERGER, J. As universidades na idade média. São Paulo: Unesp, 1990.

$1 \quad$ As transgressões desses preceitos geravam polêmicas como a causada pelo matrimônio do filósofo Abelardo com a aristocrata Louise, os quais contraíram matrimômino contrariando uma exigência aos quadros da Igreja Católica e uma conveniência da época em relação ao voto de castidade dos mestres, no século XII.

2 Conforme Robert CASTEL (1998) o surgimento das condições para a constituição da relação salarial moderna só ocorreu no século XX, entretanto, já havia embriões dela nas sociedades pré-industriais, pois “(...)esses 'vestígios' tiveram tanta existência quanto a relação salarial 'fordista'. Certamente não tiveram sua coerência e não exerceram a mesma hegemonia sobre as relações de trabalho (...) Porém a questão é exatamente compreender isso. Reativar esses 'vestígios' de assalariamento na sociedade pré-industrial, isto é, a grande impotência do conjunto dos assalariados de então” (p. 145-6).

Sobre a Universidade como formação de disponibilidades para o trabalho e mais especificamente sobre o peso do capital escolar, Cf. HEY, 2004 P. 121 e ss.

3 Nossa referência para essas afirmações é o resgate histórico sobre os conceitos dom e aptidão, em MARAFON, 2001.

Artigo recebido em: 14/05/08

Aprovado para publicação em: 30/06/09

Revista HISTEDBR On-line, Campinas, n.36, p. 153-166, dez.2009 - ISSN: 1676-2584 